\title{
Integration of DEMATEL, ANP and DEA methods for third party logistics providers' selection
}

\author{
Esra Aytaç Adalı* and Ayşegül Tuş Işık
}

\begin{tabular}{l} 
Department of Business Administration \\
\hline C H R O N I C L E \\
\hline Article history: \\
Received October 28, 2015 \\
Received in revised format \\
November 28, 2015 \\
Accepted March 22, 2016 \\
Available online \\
March 24, 2016 \\
\hline Keywords: \\
Decision Making Trial and \\
Evaluation Laboratory \\
(DEMATEL) \\
Analytic Network Process (ANP) \\
Data Envelopment Analysis \\
(DEA) \\
Third Party Logistics (TPL) \\
\end{tabular}
\begin{abstract}
A B S T R A C T
In a competitive environment many companies usually outsource their logistics functions to the Third Party Logistics (TPL) providers to focus on their core businesses. However, the selection of proper TPL provider is not an easy task because of conflicting quantitative and qualitative criteria. This study presents an integrated model based on three well-known methods Decision Making Trial and Evaluation Laboratory (DEMATEL), Analytical Network Process (ANP) and Data Envelopment Analysis (DEA) for the evaluation and selection of TPL providers. DEMATEL computes the effects between selection criteria while ANP derives the weights of each criterion related with TPL providers' selection problem. Finally DEA presents a mathematical model for ranking TPL providers alternatives with respect to various criteria. The application of integrated model is demonstrated with a case study. The novelty of this study comes from the fact that there is no research in the literature integrating DEMATEL, ANP and DEA for the TPL selection problems.
\end{abstract}

\section{Introduction}

Nowadays, many companies focus on their core businesses for their competitiveness and outsource non-core businesses in order to meet the needs of the market (Li et al., 2012). Outsourcing is a business strategy which is a managed process of transferring operations to be performed by outside suppliers (Işıklar et al., 2007). One of the transferring operations is logistics. Logistics outsourcing or Third Party Logistics (TPL) is a developing trend in the global market. TPL providers perform logistics functions of companies either completely or partially (Agguezoul et al., 2006). They can offer services such as professional logistics transportation, warehousing, logistics information system, product returns service, inventory management and product packaging (Liu \& Wang, 2009). The "third party" term comes from participating the supply chain at points between the manufacturer and the consumer of a given product. The benefits of collaboration include concentrating on the core competence, increasing the efficiency, improving the service, reducing the cost, restructuring the supply chains and establishing the marketplace legitimacy (Hertz \& Alfredsson 2003).

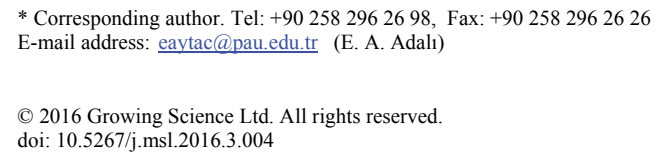


After making a decision about collaboration with a TPL provider, the next step is to select the provider. The selection of an efficient TPL provider is a complex and a time consuming decision (Agguezoul et al., 2006). To make this decision, the company has to consider different criteria to compare the possible TPL providers. This can be performed by using different methods, which take into account the conflicting criteria and help a decision maker for finding out the best alternative. In the literature, there are many studies which handle TPL selection. Göl and Çatay (2007), Karagul and Albayrakoglu (2007), $\mathrm{Fu}$ et al. (2010) used the Analytic Hierarchy Process (AHP) method for evaluating and selecting the best TPL provider on a logistics platform. Meade and Sarkis (2002) used the Analytical Network Process (ANP) method for selecting TPL providers in the context of reverse logistics. Jharkharia and Shankar (2007) used the ANP method for evaluation of the alternative providers in two steps as initial screening of the providers and final selection of a provider. Aguezzoul et al. (2006) used the ELECTRE (ELimination Et Choix Traduisant la REalité) method to classify TPL provider alternatives.

Mathematical programming methods such as linear programming, mixed integer-programming, goal programming, multiple objective programming, non-linear programming are used for TPL providers selection. Chen et al. (2001) proposed a dynamic programming model for selecting the optimal TPL warehousing contracts with space commitments. Kumar et al. (2006) formulated a multi objective programming model, using lexicographic method, for TPL allocation problem. Zhou et al. (2008) applied Data Envelopment Analysis (DEA) method to evaluate the operational efficiency of TPL which were classified into three categories as port management, transportation services and warehousing services. Hamdan and Rogers (2008) used DEA method to evaluate the efficiency of a group of TPL warehouse logistics operations. Saen (2010) proposed a DEA model for selecting Third Party Reverse Logistics (TPRL) provider with multiple dual-role factors. Azadi and Saen (2011) proposed a chanceconstrained DEA model to determine the most appropriate TPRL providers in the presence of both dual-role factors and stochastic data.

Many articles use hybrid approaches for evaluating and selecting TPL provider. Lehmusvaara et al. (1999) integrated AHP method and Mixed Integer Linear Programming model for truck carrier selection. Thakkar et al. (2005) proposed a hybrid approach of Interpretive Structural Model (ISM) and ANP method for the selection of TPL providers. Zhang et al. (2006) integrated AHP and DEA methods to specify decision makers' preference using a single scale. Cao et al. (2007a) proposed a two stage method based on the social welfare function and TOPSIS for the selection of TPL providers. Cao et al. (2007b) proposed a two stage method based on Borda Function (BF) theory and Gray Rational Analysis (GRA) for logistic outsourcing decision-making. Almeida (2007) proposed a multicriteria model based on utility function and ELECTRE method for outsourcing contracts selection. Liou and Chuang (2010) proposed a hybrid model based on DEMATEL (Decision Making Trial and Evaluation Laboratory), ANP and VIKOR (Multi-criteria Optimization and Compromise Solution) methods for TPL selection. Guoyi and Xiaohua (2011) integrated the AHP method and information entropy model to evaluate the TPL providers. Jayant et al. (2014) developed hybrid approach based on AHP and TOPSIS methods for the selection and evaluation of TPRL providers.

To model uncertainty of selection problems fuzzy methods are added to individual and hybrid approaches. Bottani and Rizzi (2006) applid fuzzy TOPSIS method for ranking and selecting the TPL providers. Qureshi et al. (2007) used TOPSIS method with interval data for TPL providers. Işıklar et al. (2007) integrated case-based reasoning, rule-based reasoning and compromise programming techniques in fuzzy environment for effective TPL evaluation and selection. Efendigil et al. (2008) used a two-phase model based on artificial neural networks and fuzzy logic in a holistic manner to determine the most appropriate TPRL provider. Çakır et al. (2009) and Soh (2010) used a fuzzy AHP model for TPL provider selection. Govindan et al. (2010) solved the TPRL provider's selection problem with fuzzy ELECTRE II method. Li et al. (2008) proposed fuzzy ANP method to select a proper TPL provider. Büyüközkan et al. (2008) used fuzzy AHP and fuzzy TOPSIS methods to select strategic 
alliance partner. Kannan et al. (2009) used ISM and fuzzy TOPSIS method for the TPRL provider selection. Liu and Wang (2009) proposed an integrated fuzzy approach for the evaluation and selection of TPL providers. Firstly, they used fuzzy Delphi method to identify important evaluation criteria then applied fuzzy inference method to eliminate unsuitable TPL providers. Finally they developed a fuzzy linear assignment approach for the final selection. Gupta et al. (2010) used fuzzy Delphi method to determine the most important criteria and most likely TPL providers and fuzzy TOPSIS to select the best TPL provider. Lei and Long (2011) proposed a method based on balanced scorecard and combined fuzzy AHP with extenics.

A literature review shows the complexity of the TPL provider selection problems because of several conflicting factors. This study presents the integration of DEMATEL, ANP and DEA methods which consider various criteria to be taken into account in this issue. The main goal is to assist efficiently the decision makers in determining the most appropriate TPL provider. Firstly, DEMATEL is employed to compute the effects among selection criteria. Then ANP is used to calculate the weights of each criterion related with TPL provider selection problem. Finally, DEA is employed to present a mathematical model for calculating the relative efficiency score and also ranking potential TPL providers.

The rest of this study is organized as follows. Section 2 shortly provides the methodological background for DEMATEL, ANP and DEA respectively. In Section 3, the application of integrated three stage method is demonstrated with a case company. Lastly in Section 4 results of the application are presented and recommendations for future studies are discussed.

\section{Integration of DEMATEL, ANP and DEA}

In this section the concepts of DEMATEL, ANP and DEA are introduced.

\subsection{Decision Making Trial and Evaluation Laboratory (DEMATEL)}

DEMATEL (Gabus \& Fontela, 1972, 1973; Fontela \& Gabus, 1976) is a method for building and analyzing a comprehensible structural model involving relationships between the causes and effects of criteria with matrices or digraphs (Wu \& Lee, 2007; Tseng, 2009). It is supposed that a problem contains a set of criteria $\left(\mathrm{C}_{1}, \mathrm{C}_{2}, \ldots, \mathrm{C}_{\mathrm{n}}\right)$ and the particular pair-wise relations are established for modelling with respect to a mathematical relation. The steps of DEMATEL are described as follows (Tseng, 2009):

Step 1 The direct relation matrix $(Z)$ is generated. The pair-wise comparison scale that decision makers use while evaluating the criteria may be defined as five levels as shown in Table 1.

\section{Table 1}

Pair-wise comparison scale

\begin{tabular}{ll}
\hline Score & Definition \\
\hline 0 & No influence \\
1 & Low influence \\
2 & Medium influence \\
3 & High influence \\
4 & Very high influence \\
\hline
\end{tabular}

The direct relation matrix $(Z)$ is constructed by the degrees of relative impacts derived from the pairwise comparisons and presented in Fig. 1. In this matrix, $z_{i j}$ denotes the degree of impacts of the criterion $i$ on the criterion $j$. All main diagonal elements $z_{i j}$ of $Z$ are zero. 


$$
Z=\left[\begin{array}{cccccc}
z_{11} & z_{12} & \cdot & \cdot & \cdot & z_{1 n} \\
z_{21} & z_{22} & \cdot & \cdot & \cdot & z_{2 n} \\
\cdot & \cdot & \cdot & & & \cdot \\
\cdot & \cdot & & \cdot & & \cdot \\
\cdot & \cdot & & & \cdot & \cdot \\
z_{n 1} & z_{n 2} & \cdot & \cdot & \cdot & z_{n n}
\end{array}\right]
$$

Fig. 1. nxn direct relation matrix $(Z)$

If there is more than one decision maker, it is needed to aggregate the direct relation matrices of decision makers. Aggregated $Z$ is computed by Eq. (1). In Eq. (1), $H$ shows the number of the decision makers.

$$
\mathrm{Z}=\frac{\sum_{\mathrm{h}=1}^{\mathrm{H}} \mathrm{Z}^{\mathrm{h}}}{\mathrm{H}} \quad \mathrm{h}=1,2, \ldots, \mathrm{H}
$$

Each element of the aggregated $Z$ is the mean of the same elements in the different direct relation matrices of the decision makers. All operations are run through aggregated $Z$.

Step $2 \mathrm{Z}$ is normalized through the Eq. (2) and normalized direct relation matrix $(X)$ is computed.

$$
X=s . Z \quad s=\min \left[\frac{1}{\max _{i} \sum_{j=1}^{n}\left|z_{i j}\right|}, \frac{1}{\max _{j} \sum_{i=1}^{n}\left|z_{i j}\right|}\right] \mathrm{i}, \mathrm{j}=1,2, \ldots, \mathrm{n}
$$

Step 3 The total relation matrix $(T)$ is acquired by Eq. (3):

$$
T=X(I-X)^{-1}
$$

In this equation, $I$ indicates identity matrix and this equation is obtained from following operations:

$$
\begin{aligned}
\mathrm{T} & =\mathrm{X}+\mathrm{X}^{2}+\mathrm{X}^{3} \ldots=\mathrm{X}\left(\mathrm{I}+\mathrm{X}+\mathrm{X}^{2}+\ldots\right) \\
& =\mathrm{X}\left(\frac{\mathrm{I}-\mathrm{X}^{\mathrm{m}}}{\mathrm{I}-\mathrm{X}}\right) \\
& =\mathrm{X}(\mathrm{I}-\mathrm{X})^{-1} \quad \text { when } \mathrm{m} \rightarrow \infty \mathrm{X}^{\mathrm{m}}=[0]_{\mathrm{n} \times} \\
\mathrm{T} & =\mathrm{X}(1-\mathrm{X})^{-1}
\end{aligned}
$$

Step 4 The threshold value is determined to reveal some significant influences in $T$. Only the criteria, whose effects in $T$ are greater than threshold value, should be chosen and shown in a network relation map. Let $t_{i j}$ be the elements of $T$ like in Eq. (4), then the sum of rows and columns $\left(D_{i}\right.$ and $\left.R_{i}\right)$ are computed by Eq.(5) and (6), respectively.

$$
\begin{aligned}
& T=\left[t_{i j}\right]_{n \times n} \quad i, j=1,2, \ldots, n \\
& D_{i}=\left[\sum_{i=1}^{n} t_{i j}\right]_{n \times 1}=\left[t_{i}\right]_{n \times 1}
\end{aligned}
$$




$$
\mathrm{R}_{\mathrm{i}}=\left[\sum_{\mathrm{j}=1}^{\mathrm{n}} \mathrm{t}_{\mathrm{ij}}\right]_{1 \mathrm{xn}}=\left[\mathrm{t}_{\mathrm{j}}\right]_{1 \mathrm{xn}}
$$

$D_{l}$ indicates the sum of direct and indirect impacts of the first criterion over other criteria. $R_{l}$ indicates the sum of direct and indirect impacts that first criterion receives from other criteria. Then, $D_{i}+R_{i}$ and $D_{i}-R_{i}$ values are calculated for all criteria. $D_{i}+R_{i}$ represents the strength of relationships between criteria whereas $D_{i}-R_{i}$ represents the strength of influences among criteria. If $D_{i}-R_{i}$ has a negative value, then criterion is in effect group and called net receiver. If $D_{i}-R_{i}$ has a positive value, then criterion is in cause group and called net causer.

The network relation map is acquired by mapping the ordered pairs of $D_{i}+R_{i}$ and $D_{i}-R_{i}$. This graph provides a visible structural model of complicated causal relationships between criteria and an insight for the solution of the problem (Tsai \& Hsu, 2010).

\subsection{Analytic Network Process (ANP)}

The Analytic Network Process (ANP), developed by Saaty (1996), deals with the decisions without the assumptions of the independencies of higher level elements from lower level elements and also the independencies of the elements within the same level. It allows a network structure including dependence and feedback among the elements of a decision model. Steps of ANP are summarized as follows:

Step 1 Firstly criteria/sub-criteria and alternatives are defined, then the cluster of elements is determined. Network is formed by the relationship between clusters and within elements in each cluster.

Step 2 The pair-wise comparison is constructed by Saaty's (1996) 1-9 scale shown in Table 2.

\section{Table 2}

Saaty's 1-9 scale

\begin{tabular}{cl}
\hline Intensity of importance & Definition \\
\hline 1 & Equal importance \\
3 & Moderate importance \\
5 & Strong importance \\
7 & Very strong importance \\
9 & Extreme importance \\
$2,4,6,8$ & Intermediate values \\
\hline
\end{tabular}

This pair-wise comparison yields an $n \times n$ matrix $(A)$ as follows:

$$
A=\left[a_{i j}\right]=\left[\begin{array}{cccc}
1 & a_{12} & \cdots & a_{1 n} \\
1 / a_{12} & 1 & \cdots & a_{2 n} \\
\vdots & \vdots & \ddots & \vdots \\
1 / a_{1 n} & 1 / a_{2 n} & \cdots & 1
\end{array}\right]
$$

$\mathrm{a}_{\mathrm{ij}}=\mathrm{w}_{\mathrm{i}} / \mathrm{w}_{\mathrm{j}}, i, j=1,2, \ldots, n$ has positive entries everywhere and satisfies the reciprocal property $\mathrm{a}_{\mathrm{ji}}=1 / \mathrm{a}_{\mathrm{ij}}$. Any matrix with this property is called a reciprocal matrix. In addition $\mathrm{A}$ is consistent because the following condition is satisfied (Saaty, 1990):

$$
\mathrm{a}_{\mathrm{jk}}=\mathrm{a}_{\mathrm{ik}} / \mathrm{a}_{\mathrm{ij}} \quad \mathrm{i}, \mathrm{j}, \mathrm{k}=1,2, \ldots, \mathrm{n}
$$

According to Saaty (1990) the largest eigenvalue $\lambda_{\max }$ would be: 


$$
\lambda_{\max }=\sum_{\mathrm{j}=1}^{\mathrm{n}} \mathrm{a}_{\mathrm{ij}} \mathrm{w}_{\mathrm{ij}} / \mathrm{w}_{\mathrm{i}}
$$

Saaty (1990) proposed a consistency index (CI) and consistency ratio (CR) as seen in Eq. (10) and Eq. (11):

$$
\begin{aligned}
& \mathrm{CI}=\left(\lambda_{\text {max }}-\mathrm{n}\right) /(\mathrm{n}-1) \\
& \mathrm{CR}=\mathrm{CI} / \mathrm{RI}
\end{aligned}
$$

Here $R I$ is the average $\mathrm{CI}$ over numerous random entries of the reciprocal matrices with the same orders. If $\mathrm{CR} \leq 0,1$, then the estimate is accepted, otherwise comparison matrix is revised until $\mathrm{CR} \leq 0,1$ to improve consistency (Tsai \& Hsu, 2010).

Step 3 Unweighted supermatrix is formed as seen in Fig. 2.

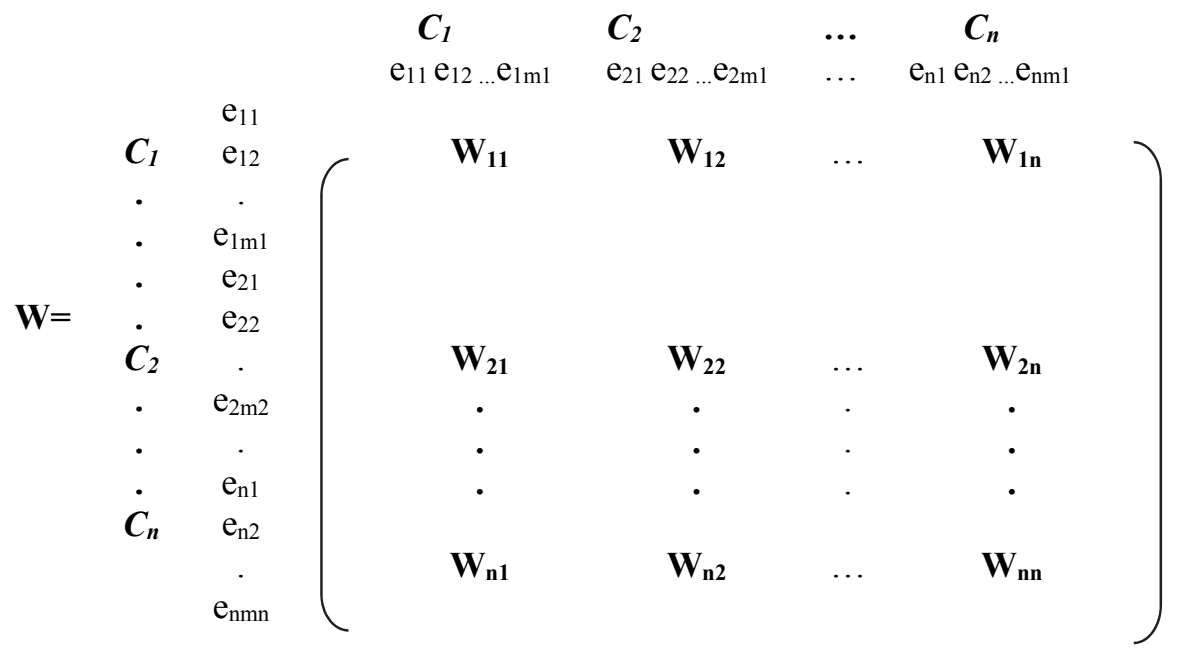

Fig. 2. Unweighted supermatrix

Unweighted supermatrix's columns contain the priorities derived from the pair-wise comparisons of the elements. To obtain a stochastic matrix, i.e., each column sums to one, the blocks of the unweighted supermatrix should be multiplied by the corresponding cluster priority (Tseng, 2010).

Step 4 After the weighted supermatrix is obtained, it can be raised to limiting powers to calculate the overall priority weights. The best alternative is selected by this limit matrix. Importance weights of alternatives, criteria are determined and the highest importance weight shows the best alternative.

\subsection{Data Envelopment Analysis (DEA)}

DEA, developed by Charnes et al. (1978), is a technique to measure the relative efficiency of a set of comparable units called decision making units (DMUs), which include profit or non-profit organizations, departments or branches of organizations, or even individuals. DEA calculates the relative efficiency of a DMU which is the ratio of the weighted sum of its outputs to the weighted sum of its inputs. The most efficient DMU is rated as an efficiency score of one, whereas all other less efficient DMUs are scored somewhere between zero and one (Min \& Park, 2008). 
In the application of DEA as a ranking tool, the DMUs, outputs and inputs are replaced with the alternatives, maximization criteria and minimization criteria respectively (Tohumcu \& Karasakal, 2010). The general efficiency measure used by DEA is expressed as (Doyle \& Green, 1993):

$$
\mathrm{E}_{\mathrm{ks}}=\frac{\sum_{\mathrm{y}} \mathrm{O}_{\mathrm{sy}} \mathrm{v}_{\mathrm{ky}}}{\sum_{\mathrm{x}} \mathrm{I}_{\mathrm{sx}} \mathrm{u}_{\mathrm{kx}}}
$$

In this formula $\mathrm{E}_{\mathrm{ks}}$ is the efficiency or productivity measure of alternative $s$, using the weights of "test" alternative $k$, where the test alternative is the unit whose efficiency is to be evaluated; $\mathrm{O}_{\text {sy }}$ is the value of output $y$ for alternative $s$; $\mathrm{I}_{\mathrm{sx}}$ is the value for input $x$ of alternative $s$; $\mathrm{v}_{\mathrm{ky}}$ is the weight assigned to alternative $k$ for output $y$ and $u_{\mathrm{kx}}$ is the weight assigned to alternative $k$ for input $x$.

The frequently used DEA model is the CCR model, which assumes constant returns to scale (CRS). According to the formulation of basic CCR model given in Eq. (13), the objective is to maximize the efficiency value of a test alternative $k$, from among a reference set of alternatives $s$, by selecting the optimal weights associated with the input and output measures.

$$
\begin{array}{ll}
\max \quad E_{k k}= & \frac{\sum_{y} O_{k y} v_{k y}}{\sum_{x} I_{k x} u_{k x}} \\
\text { s.t. } & E_{k s} \leq 1 \\
& u_{k x}, v_{k y} \geq 0
\end{array} \quad \forall s
$$

CCR model which is stated in fractional programming model in Eq. (13) is then transformed into an equivalent ordinary linear programming model and obtained as Eq. (14):

$$
\begin{aligned}
& \max E_{k k}=\sum_{y} O_{k y} v_{k y} \\
& \text { s.t. } \quad E_{k s} \leq 1 \quad \forall s \\
& \sum_{x} I_{k x} u_{k x}=1 \\
& u_{k x}, v_{k y} \geq 0
\end{aligned}
$$

If "technical efficiency" value $\left(E_{\mathrm{kk}}^{*}\right)$ is equal to 1 ; no other alternative is more efficient than alternative $k$ for its selected weights. If it is less than 1 , there is at least one other alternative that is more efficient for the optimal set of weights determined by the model. This formulation is executed $s$ times, once for each alternative (Sarkis, 2000; Sarkis \& Talluri, 2002).

CCR model does not provide any insights to discriminate among the efficient alternatives and rank them. A ranking DEA model for the best alternative proposed by Andersen and Petersen (1993) is presented. This model has been called as 'reduced CCR (RCCR)' by Sarkis (2000).

$$
\begin{array}{ll}
\max \quad E_{k k}= & \sum_{y} O_{k y} v_{k y} \\
\text { s.t. } & E_{k s} \leq 1 \\
& \sum_{x} I_{k x} u_{k x}=1 \\
& u_{k x}, v_{k y} \geq 0
\end{array} \quad \forall s \neq k
$$

In this model, the test unit is eliminated from the constraint set and technically efficient scores are greater than 1 .

Sometimes weight restrictions may be added to the ranking DEA hence managerial preferences are taken into account. There are several methods for weight restrictions in DEA modeling. In this study the method proposed by Sarkis (2000) is used and it considers assurance regions (AR). Developing AR constraints requires defining upper bound (UB) and lower bound (LB) for each input and output weight. 
In this study LB and UB on criteria weights are determined by ANP. LB and UB values for each weight define AR constraints that relate the weights of minimizing (or maximizing) criteria and their bounds to each other. The AR constraint sets derived from LB and UB values can be expressed as:

$$
\mathrm{v}_{\mathrm{i}} \geq \frac{\mathrm{LB}_{\mathrm{i}}}{\mathrm{UB}_{\mathrm{j}}} \mathrm{v}_{\mathrm{j}} \text { and } \mathrm{v}_{\mathrm{i}} \leq \frac{\mathrm{UB}_{\mathrm{i}}}{\mathrm{LB}_{\mathrm{j}}} \mathrm{v}_{\mathrm{j}}
$$

These constraints are added to Eq. 15 and new model is called RCRR/AR model. The number of additional constraints required to help define the AR is equal to $\frac{I(I-1)}{2}+\frac{O(O-1)}{2}$. In this formula $I$ and $O$ are the numbers of inputs and outputs respectively (Sarkis, 2000; Sarkis \& Talluri, 2002).

The conceptual flow of the DEMATEL, ANP and DEA methods used in this study is presented in Fig. 3. It requires a three-stage framework using these methods in each stage respectively.

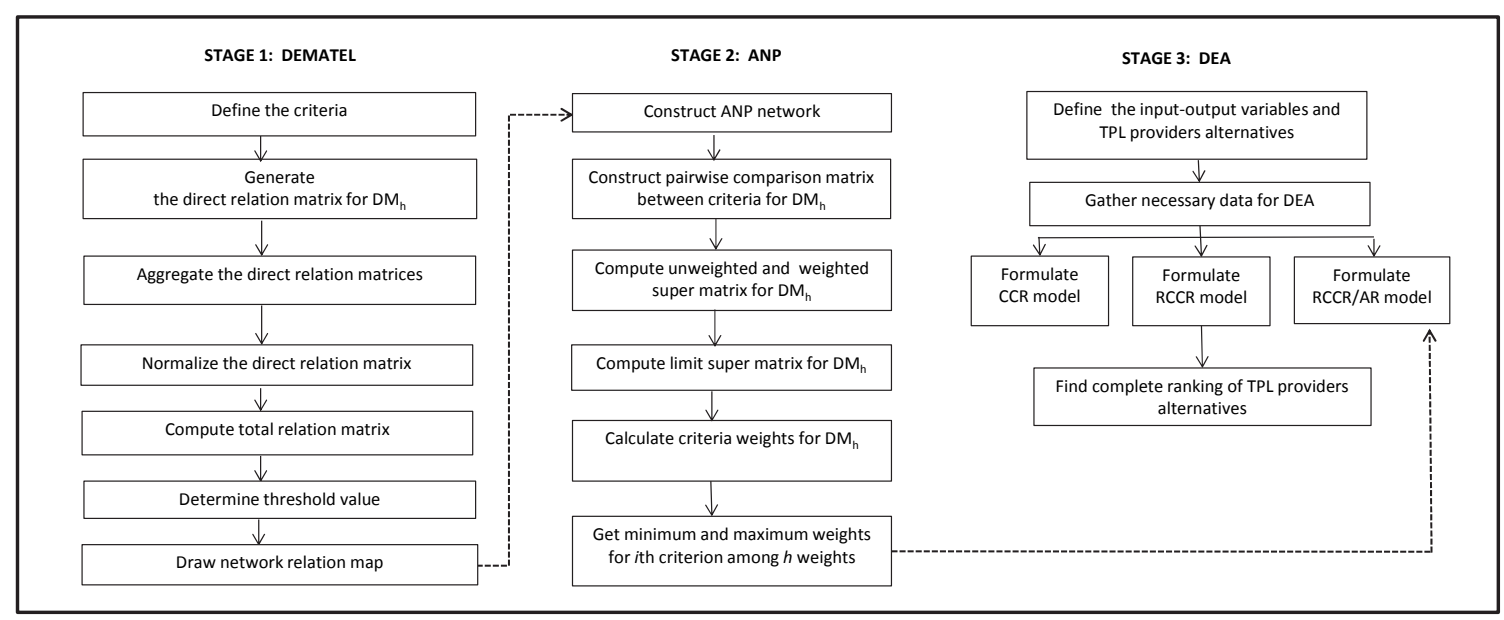

Fig. 3. The integration of DEMATEL, ANP and DEA

\section{Application}

The integration of DEMATEL, ANP and DEA is applied to a TPL provider selection of a textile company which is one of the textile exporters in Turkey. A proper TPL provider selection is needed for this company in terms of introducing its products into the global market. For this purpose a committee of decision makers $\left(\mathrm{DM}_{1}, \mathrm{DM}_{2}, \mathrm{DM}_{3}\right)$ is formed firstly. Decision makers at the committee have equal stature on evaluation process and judgements of them are expressed impartially. Then the committee determine a specific product of the company to be introduced for making a rational comparison between TPL providers. Finally 10 criteria that are used in evaluating TPL providers are determined by the committee. These criteria are as follows:

Price $\left(C_{1}\right)$ : It is the price expressed in USD for the current product and service given by the TPL providers.

The insurance of the product packaging and transportation $\left(C_{2}\right)$ : It is the insurance cost expressed in USD given by the TPL providers for lost or damaged goods during packaging and transportation.

Delivery time $\left(C_{3}\right)$ : On-time delivery is important for the satisfaction of the customer. Delivery time is the amount of time expressed in days that it takes for goods that have been bought to arrive at the place where they are wanted. In other words it is the time between placing and shipping the customers' order. 
Attitudes of service providers $\left(C_{4}\right)$ : This criterion encompasses the willingness of the service providers to the customers in terms of information sharing and communication. For this criterion 5 level Likert scale (1: very low; 2 : low; 3 : medium; 4: high; 5 : very high) is used.

Extensity of transportation network $\left(C_{5}\right)$ : The geographic area served by the TPL provider is an important issue. Wide geographic spread and range of services offered by the provider are desirable as these create enhanced access to market and many more avenues to the user. For this criterion the distribution of the offices/branches/warehouses of the service provider according to the suppliers of the company is considered.

Expertise of the TPL provider in the field $\left(C_{6}\right)$ : It shows the experience of TPL providers in logistics. Experience includes specialization in industry, special expertise, market knowledge. So the references and the previous experiences are taken into consideration for this criterion and it is expressed as the total number of projects completed succesfully and consultant references.

Existence of logistic information system $\left(C_{7}\right)$ : Mutual trust-based information sharing between the customer and TPL provider is necessary. This requirement is satisfied by establishing information technology systems. This criterion is expressed as 1 and 0 where number 1 and 0 show the existence of logistic information system and non-existence respectively.

Quality assurance systems $\left(C_{8}\right)$ : This criterion gives an idea about the product performance, accuracy, quality awareness, inspection methods, continuous improvement. It is expressed as the number of quality certificates.

Reputation ( $\left.C_{9}\right)$ : It refers to the opinion of the customers about how good TPL provider is in satisfying the needs of the customer. This criterion is expressed as the number of web visitors.

Financial performance ( $\left.C_{10}\right)$ : It measures the results of a company's policies and operations in monetary terms. These results are reflected in the company's return on investment, return on assets, value added.

After determining the criteria, ten TPL provider alternatives $\left(\mathrm{A}_{1}, \mathrm{~A}_{2}, \ldots, \mathrm{A}_{10}\right)$ are taken into consideration. Finally TPL provider selection problem of the textile company is solved with the proposed approach that combines DEMATEL, ANP and DEA methods.

\subsection{DEMATEL Application}

Direct relation matrices for each decision maker are obtained by using the scores in Table 1 . Aggregated direct relation matrix shown in Table 3, normalized aggregated direct relation matrix $(X)$ and total relation matrix ( $T$ ) are calculated by Eq. (1), (2) and (3) respectively.

Table 3

Aggregated direct relation matrix

\begin{tabular}{|c|c|c|c|c|c|c|c|c|c|c|}
\hline & $\mathrm{C}_{1}$ & $\mathrm{C}_{2}$ & $\mathrm{C}_{3}$ & $\mathrm{C}_{4}$ & $\mathrm{C}_{5}$ & $\mathrm{C}_{6}$ & $\mathrm{C}_{7}$ & $\mathrm{C}_{8}$ & $\mathrm{C}_{9}$ & $\mathrm{C}_{10}$ \\
\hline $\mathrm{C}_{1}$ & 0,00 & 1,33 & 2,33 & 0,67 & 0,00 & 0,00 & 1,00 & 0,67 & 0,33 & 3,33 \\
\hline $\mathrm{C}_{2}$ & 2,67 & 0,00 & 0,00 & 0,00 & 0,00 & 0,00 & 0,00 & 3,33 & 2,33 & 2,67 \\
\hline $\mathrm{C}_{3}$ & 3,00 & 0,67 & 0,00 & 0,00 & 0,00 & 0,00 & 0,00 & 3,33 & 3,67 & 2,67 \\
\hline $\mathrm{C}_{4}$ & 0,33 & 0,00 & 0,33 & 0,00 & 0,00 & 0,33 & 0,67 & 2,33 & 3,00 & 2,33 \\
\hline $\mathrm{C}_{5}$ & 1,67 & 1,67 & 3,67 & 0,00 & 0,00 & 0,67 & 3,33 & 2,33 & 3,33 & 3,00 \\
\hline $\mathrm{C}_{6}$ & 0,67 & 1,33 & 2,67 & 2,67 & 2,33 & 0,00 & 3,33 & 1,33 & 3,67 & 3,67 \\
\hline $\mathrm{C}_{7}$ & 2,33 & 0,00 & 2,67 & 2,33 & 0,00 & 2,00 & 0,00 & 3,33 & 3,33 & 3,33 \\
\hline $\mathrm{C}_{8}$ & 2,00 & 3,00 & 1,67 & 1,67 & 0,67 & 1,00 & 1,00 & 0,00 & 3,33 & 3,00 \\
\hline $\mathrm{C}_{9}$ & 1,33 & 0,67 & 1,67 & 1,67 & 1,00 & 2,33 & 1,00 & 1,00 & 0,00 & 3,67 \\
\hline $\mathrm{C}_{10}$ & 1,33 & 2,33 & 2,33 & 2,33 & 3,33 & 1,67 & 3,67 & 1,00 & 3,00 & 0,00 \\
\hline
\end{tabular}


Total relation matrix $(T)$ is shown in Table 4. Threshold value is determined as 0.13 by the decision makers. This number should be the most appropriate value to acquire a suitable relationship. If the threshold value is too low, there will be too many factors and complex relationships in the whole system; the relationship is not obvious when the value is too high (Tsai and Hsu 2010).

\section{Table 4}

Total relation matrix

\begin{tabular}{lccccccccccc}
\hline & $\mathrm{C}_{1}$ & $\mathrm{C}_{2}$ & $\mathrm{C}_{3}$ & $\mathrm{C}_{4}$ & $\mathrm{C}_{5}$ & $\mathrm{C}_{6}$ & $\mathrm{C}_{7}$ & $\mathrm{C}_{8}$ & $\mathrm{C}_{9}$ & $\mathrm{C}_{10}$ \\
\hline $\mathrm{C}_{1}$ & 0,05 & 0,08 & 0,13 & 0,06 & 0,03 & 0,03 & 0,08 & 0,08 & 0,09 & 0,19 \\
$\mathrm{C}_{2}$ & 0,14 & 0,05 & 0,06 & 0,05 & 0,03 & 0,04 & 0,05 & 0,16 & 0,16 & 0,18 \\
$\mathrm{C}_{3}$ & 0,17 & 0,08 & 0,07 & 0,05 & 0,04 & 0,04 & 0,06 & 0,17 & 0,22 & 0,20 \\
$\mathrm{C}_{4}$ & 0,06 & 0,04 & 0,07 & 0,04 & 0,03 & 0,05 & 0,07 & 0,13 & 0,18 & 0,16 \\
$\mathrm{C}_{5}$ & 0,16 & 0,13 & 0,23 & 0,08 & 0,05 & 0,09 & 0,20 & 0,19 & 0,27 & 0,27 \\
$\mathrm{C}_{6}$ & 0,13 & 0,12 & 0,21 & 0,18 & 0,14 & 0,07 & 0,21 & 0,17 & 0,30 & 0,30 \\
$\mathrm{C}_{7}$ & 0,17 & 0,07 & 0,19 & 0,16 & 0,06 & 0,13 & 0,09 & 0,21 & 0,26 & 0,27 \\
$\mathrm{C}_{8}$ & 0,15 & 0,16 & 0,14 & 0,12 & 0,07 & 0,08 & 0,11 & 0,09 & 0,24 & 0,24 \\
$\mathrm{C}_{9}$ & 0,12 & 0,08 & 0,14 & 0,12 & 0,08 & 0,12 & 0,11 & 0,11 & 0,12 & 0,24 \\
$\mathrm{C}_{10}$ & 0,15 & 0,15 & 0,19 & 0,16 & 0,17 & 0,12 & 0,21 & 0,16 & 0,27 & 0,18 \\
\hline
\end{tabular}

The structural derivatives $\left(D_{i}\right.$ and $\left.R_{j}\right)$ from DEMATEL method are shown in Table 5. Also the ranking of criteria according to $D_{i}+R_{i}$ and $D_{i}-R_{i}$ values are shown in this table. Finally, the network relation map of these ten criteria and the final influence result is shown in Fig. 4.

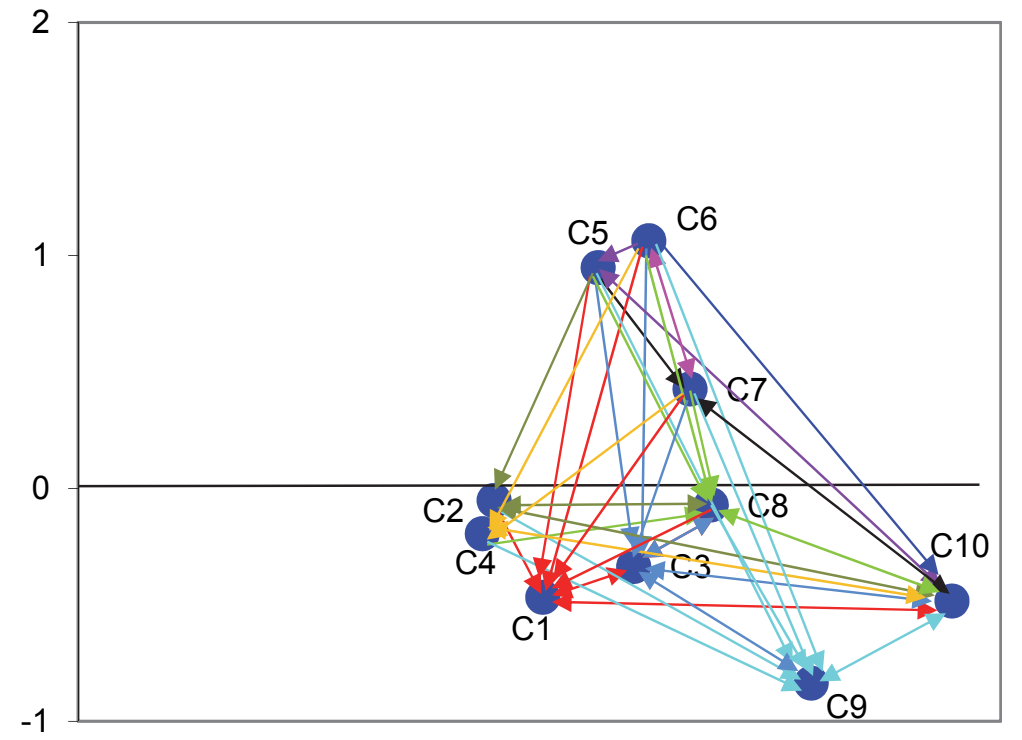

\section{Table 5}

Fig. 4. Network relation map

$\mathrm{D}_{\mathrm{i}}+\mathrm{R}_{\mathrm{i}}$ and $\mathrm{D}_{\mathrm{i}}-\mathrm{R}_{\mathrm{i}}$ values

\begin{tabular}{lcccccc}
\hline & $\mathrm{D}_{\mathrm{i}}$ & $\mathrm{R}_{\mathrm{i}}$ & $\mathrm{D}_{\mathrm{i}}+\mathrm{R}_{\mathrm{i}}$ & Ranking & $\mathrm{D}_{\mathrm{i}}-\mathrm{R}_{\mathrm{i}}$ & Ranking \\
\hline $\mathrm{C}_{1}$ & 0,824 & 1,291 & 2,115 & 8 & $-0,467$ & 8 \\
$\mathrm{C}_{2}$ & 0,920 & 0,972 & 1,893 & 9 & $-0,052$ & 4 \\
$\mathrm{C}_{3}$ & 1,097 & 1,432 & 2,529 & 5 & $-0,335$ & 7 \\
$\mathrm{C}_{4}$ & 0,823 & 1,017 & 1,840 & 10 & $-0,194$ & 6 \\
$\mathrm{C}_{5}$ & 1,658 & 0,709 & 2,367 & 6 & 0,948 & 2 \\
$\mathrm{C}_{6}$ & 1,831 & 0,767 & 2,598 & 7 & 1,063 & 1 \\
$\mathrm{C}_{7}$ & 1,606 & 1,179 & 2,786 & 4 & 0,427 & 3 \\
$\mathrm{C}_{8}$ & 1,406 & 1,476 & 2,882 & 3 & $-0,070$ & 5 \\
$\mathrm{C}_{9}$ & 1,250 & 2,086 & 3,337 & 2 & $-0,836$ & 10 \\
$\mathrm{C}_{10}$ & 1,748 & 2,230 & 3,978 & 1 & $-0,483$ & 9 \\
\hline & & & & & &
\end{tabular}


According to $D_{i}-R_{i}$ values in Table $5, \mathrm{C}_{1}, \mathrm{C}_{2}, \mathrm{C}_{3}, \mathrm{C}_{4}, \mathrm{C}_{8}, \mathrm{C}_{9}$ and $\mathrm{C}_{10}$ are grouped as effect group while $\mathrm{C}_{5}, \mathrm{C}_{6}$ and $\mathrm{C}_{7}$ are grouped as cause group.

\subsection{ANP Application}

After determining the relationship structure among the 10 criteria with DEMATEL, ANP method is applied to calculate the weight of each criterion. After forming network structure, the pair-wise comparisons are made with Saaty's 1 to 9 scale by the first decision maker. The software named Super Decisions is applied to aid the calculations. After computing the results of assessments, it is seen that the consistency ratio (CR) values are all acceptable. Then unweighted and weighted super matrices are obtained respectively. Finally weighted super-matrix is raised to limiting powers to obtain limit matrix as seen in Table 6. According to this limit matrix the overall priority weights are determined for the first decision maker. The same ANP steps are repeated for the second and third decision makers and their own sub-criteria weights are obtained. By comparing each decision maker's own sub-criteria weights, the minimum and maximum criteria weights for each criterion are determined and shown in Table 7. These values will be used as lower and upper bounds of AR constraint in RCCR/AR model of DEA in the third stage of the application.

Table 6

Limit matrix for $\mathrm{DM}_{1}$

\begin{tabular}{|c|c|c|c|c|c|c|c|c|c|c|}
\hline & $\mathrm{C}_{1}$ & $\mathrm{C}_{2}$ & $\mathrm{C}_{3}$ & $\mathrm{C}_{4}$ & $\mathrm{C}_{5}$ & $\mathrm{C}_{6}$ & $\mathrm{C}_{7}$ & $\mathrm{C}_{8}$ & $\mathrm{C}_{9}$ & $\mathrm{C}_{10}$ \\
\hline $\mathrm{C}_{1}$ & 0.28029 & 0.28029 & 0.28029 & 0.28029 & 0.28029 & 0.28029 & 0.28029 & 0.28029 & 0.28029 & 0.28029 \\
\hline $\mathrm{C}_{2}$ & 0.06260 & 0.06260 & 0.06260 & 0.06260 & 0.06260 & 0.06260 & 0.06260 & 0.06260 & 0.06260 & 0.06260 \\
\hline $\mathrm{C}_{3}$ & 0.32123 & 0.32123 & 0.32123 & 0.32123 & 0.32123 & 0.32123 & 0.32123 & 0.32123 & 0.32123 & 0.32123 \\
\hline $\mathrm{C}_{4}$ & 0.00687 & 0.00687 & 0.00687 & 0.00687 & 0.00687 & 0.00687 & 0.00687 & 0.00687 & 0.00687 & 0.00687 \\
\hline $\mathrm{C}_{5}$ & 0.00490 & 0.00490 & 0.00490 & 0.00490 & 0.00490 & 0.00490 & 0.00490 & 0.00490 & 0.00490 & 0.00490 \\
\hline $\mathrm{C}_{6}$ & 0.00369 & 0.00369 & 0.00369 & 0.00369 & 0.00369 & 0.00369 & 0.00369 & 0.00369 & 0.00369 & 0.00369 \\
\hline $\mathrm{C}_{7}$ & 0.01167 & 0.01167 & 0.01167 & 0.01167 & 0.01167 & 0.01167 & 0.01167 & 0.01167 & 0.01167 & 0.01167 \\
\hline $\mathrm{C}_{8}$ & 0.05376 & 0.05376 & 0.05376 & 0.05376 & 0.05376 & 0.05376 & 0.05376 & 0.05376 & 0.05376 & 0.05376 \\
\hline $\mathrm{C}_{9}$ & 0.04397 & 0.04397 & 0.04397 & 0.04397 & 0.04397 & 0.04397 & 0.04397 & 0.04397 & 0.04397 & 0.04397 \\
\hline $\mathrm{C}_{10}$ & 0.21101 & 0.21101 & 0.21101 & 0.21101 & 0.21101 & 0.21101 & 0.21101 & 0.21101 & 0.21101 & 0.21101 \\
\hline
\end{tabular}

Table 7

Range limits for criteria weights

\begin{tabular}{lll}
\hline & Min & Max \\
\hline $\mathbf{C}_{\mathbf{1}}$ & 0,276 & 0,280 \\
$\mathbf{C}_{\mathbf{2}}$ & 0,014 & 0,063 \\
$\mathbf{C}_{\mathbf{3}}$ & 0,312 & 0,376 \\
$\mathbf{C}_{\mathbf{4}}$ & 0,007 & 0,010 \\
$\mathbf{C}_{\mathbf{5}}$ & 0,005 & 0,010 \\
$\mathbf{C}_{\mathbf{6}}$ & 0,003 & 0,004 \\
$\mathbf{C}_{\mathbf{7}}$ & 0,011 & 0,012 \\
$\mathbf{C}_{\mathbf{8}}$ & 0,033 & 0,054 \\
$\mathbf{C}_{\mathbf{9}}$ & 0,044 & 0,132 \\
$\mathbf{C}_{\mathbf{1 0}}$ & 0,135 & 0,211 \\
\hline
\end{tabular}

\subsection{DEA Application}

In this stage the relative efficiency scores of the TPL providers are analyzed through different DEA models after determining the relative weight of each criterion. This stage begins with applying basic DEA (unrestricted) model to 10 homogeneous TPL provider alternatives that have similar processes, products, inputs and outputs. For applying basic DEA model firstly 10 criteria are divided into two categories as inputs and outputs. 
As a result of this division two common inputs [price $\left(\mathrm{C}_{1}\right)$, delivery time $\left(\mathrm{C}_{3}\right)$ ] and eight common outputs [the insurance of the product packaging and transportation $\left(\mathrm{C}_{2}\right)$, attitudes of service providers $\left(\mathrm{C}_{4}\right)$, extensity of transportation network $\left(\mathrm{C}_{5}\right)$, expertise of the TPL provider in the field $\left(\mathrm{C}_{6}\right)$, existence of logistic information system $\left(\mathrm{C}_{7}\right)$, quality assurance systems $\left(\mathrm{C}_{8}\right)$, reputation $\left(\mathrm{C}_{9}\right)$, financial performance $\left.\left(\mathrm{C}_{10}\right)\right]$ are used in this study. Then data are collected for 10 homogeneous TPL providers in Turkey and shown in Table 8.

\section{Table 8}

Criteria data of TPL providers

\begin{tabular}{lcccccccccc}
\hline & $\mathrm{C}_{1}$ & $\mathrm{C}_{2}$ & $\mathrm{C}_{3}$ & $\mathrm{C}_{4}$ & $\mathrm{C}_{5}$ & $\mathrm{C}_{6}$ & $\mathrm{C}_{7}$ & $\mathrm{C}_{8}$ & $\mathrm{C}_{9}$ & $\mathrm{C}_{10}$ \\
\hline $\mathrm{A}_{1}$ & 23,5 & 0,24 & 2 & 2 & 200 & 69 & 1 & 5 & 13884 & 7246 \\
$\mathrm{~A}_{2}$ & 16 & 0,16 & 2,5 & 4 & 220 & 46 & 1 & 2 & 3710 & 38530 \\
$\mathrm{~A}_{3}$ & 4,4 & 0,04 & 4 & 3 & 230 & 42 & 1 & 3 & 1025375 & 39304 \\
$\mathrm{~A}_{4}$ & 45 & 0,45 & 3 & 5 & 240 & 108 & 1 & 1 & 1498401 & 53105 \\
$\mathrm{~A}_{5}$ & 25 & 0,2 & 4 & 4 & 220 & 33 & 1 & 4 & 125129 & 11256 \\
$\mathrm{~A}_{6}$ & 28 & 0,15 & 5 & 4 & 227 & 36 & 1 & 2 & 75342 & 13400 \\
$\mathrm{~A}_{7}$ & 4,5 & 0,16 & 1,5 & 3 & 220 & 12 & 1 & 2 & 94694 & 48440 \\
$\mathrm{~A}_{8}$ & 10 & 0,02 & 2 & 2 & 212 & 20 & 1 & 2 & 91062 & 10000 \\
$\mathrm{~A}_{9}$ & 14 & 0,07 & 2 & 4 & 228 & 12 & 1 & 1 & 74822 & 35000 \\
$\mathrm{~A}_{10}$ & 8 & 0,04 & 3,5 & 3 & 227 & 17 & 1 & 1 & 645 & 18000 \\
\hline
\end{tabular}

Before processing the data in DEA, mean normalization is performed. Firstly CCR model is applied. According to final efficient scores of CCR model shown on the first column of Table 9, TPL alternatives named $A_{1}, A_{2}, A_{3}, A_{4}$ and $A_{7}$ are efficient so there is no ranking among them.

Then RCCR model is applied and ranking order is found as $A_{3}>A_{7}>A_{4}>A_{1}>A_{2}>A_{9}>A_{8}>A_{5}>A_{10}>A_{6}$ where " $>$ " means "is preferred to". Finally by using range limits of criteria weights on Table 7, AR constraints are formed and added to RCCR model. In these constraints minimum and maximum weight values of each criterion is used as upper and lower bound of each criterion weight. After solving RCCR/AR model, ranking order is found as $A_{7}>A_{3}>A_{4}>A_{9}>A_{2}>A_{1}>A_{8}>A_{5}>A_{10}>A_{6}$.

Table 9

Final efficiency scores of TPL providers

\begin{tabular}{lccc}
\hline & CCR & RCCR & RCCR/AR \\
\hline $\mathrm{A}_{1}$ & 1 & 2,3026 & 0,3054 \\
$\mathrm{~A}_{2}$ & 1 & 1,0012 & 0,3958 \\
$\mathrm{~A}_{3}$ & 1 & 7,4345 & 0,9629 \\
$\mathrm{~A}_{4}$ & 1 & 2,9255 & 0,7061 \\
$\mathrm{~A}_{5}$ & 0,5941 & 0,5941 & 0,2214 \\
$\mathrm{~A}_{6}$ & 0,4605 & 0,4605 & 0,1406 \\
$\mathrm{~A}_{7}$ & 1 & 3,5902 & 2,0816 \\
$\mathrm{~A}_{8}$ & 0,7860 & 0,7860 & 0,2852 \\
$\mathrm{~A}_{9}$ & 0,9990 & 0,9990 & 0,4061 \\
$\mathrm{~A}_{10}$ & 0,5737 & 0,5737 & 0,1986 \\
\hline
\end{tabular}

\section{Conclusion}

Logistic service providers called third-party logistics (TPL) are the main parts of the logistic process because of reducing the cost and improving the productivity and service quality of their customers. So the selection of TPL provider is important. In this study a multi criteria decision making approach based on integration of DEMATEL, ANP and DEA is used for TPL provider selection problem of a textile company. The aim of this study is to develop a systematic and integrated decision analysis approach for this problem. In this manner firstly DEMATEL is employed to compute the effects between selection criteria and acquire network relation map. Then in ANP, network relations are determined 
based on network relation map and the weights of the criteria are obtained. Finally criteria weights are transferred to the DEA model as AR constraints. According to the results, it is advised to the company to select the TPL provider A7. The company's management has found the results satisfactory and decided to select $A 7$.

The proposed approach provides several advantages to decision makers. Firstly DEMATEL analyses the selection criteria. Interdependencies and interactions among criteria are derived and also criteria are divided into two subgroups as cause and effect to develop casual relationship. By this way the complexity of a problem becomes easier and DEMATEL prepares initial input for ANP as network relation map. By the help of network relation map, ANP structures a network to handle interdependencies between criteria rather than a strict hierarchy and the number of pair-wise comparisons is reduced. ANP reflects subjective opinions of the decision makers so it is possible to transfer the managerial preferences to the performance measurement process and provide more realistic model for DEA. However sometimes subjectivity of ANP can be a disadvantage because the DEA model is dependent on the weightings provided by the decision makers. So decision makers judgement should be consistent and realistic. This situation should be satisfied by selecting of committe members carefully considering their experience and knowledge. On the other hand, adding AR constraints to the DEA model provides the integration of the weight bounds derived through ANP. Decision maker's power on the selection problem is augmented with the weight restrictions which reflect the preferences of decision makers. DEA enables decision makers to analyse and rank large number of alternatives considering criteria data. This analysis is time consuming and cumbersome in ANP because of the difficulty and the number of constructing pair-wise comparison matrix. Utilitization of RCCR/AR model measures the operational efficiency of each TPL provider alternatives, discriminates the alternatives and also provides the most proper TPL provider with the quantitative data. For complete ranking, integration of DEMATEL, ANP and DEA requires less pair-wise comparisons and computation. Results demonstrate that the integrated method provides the decision makers to take the advantage of using DEMATEL, ANP and DEA in a single framework. At the same time it assists decision makers in analyzing criteria and making an objective selection.

In future studies, the number of the criteria and the alternatives may be changed according to needs of the company for the TPL provider. If the criteria, the alternatives and the managerial judgments remain unchanged for the next periods, it will not be necessary to calculate the network relation map and ANP weights again for the same company. DEA model only will be updated with the new data and new complete ranking of TPL providers will be obtained.

On the other hand, the other multi criteria decision making methods can be used for TPL provider selection. The proposed approach can also be applied to other multi criteria decision problems of the company like; supplier selection, personnel selection, software selection, project selection, etc.

\section{References}

Aguezzoul A, Rabenasolo B, Jolly-Desodt A (2006) Multicriteria decision aid tool for third party logistics provider's selection. In: Annals of 2006 International Conference on Service Systems and Service Management, 25-27 October, Troyes, 912-916.

Almeida AT (2007) Multicriteria decision model for outsourcing contracts selection based on utility function and ELECTRE method. Computers \& Operations Research, 34(12), 3569-3574

Andersen, P., \& Petersen, N. C. (1993). A procedure for ranking efficient units in data envelopment analysis. Management Science, 39(10), 1261-1264.

Azadi, M., \& Saen, R. F. (2011). A new chance-constrained data envelopment analysis for selecting third-party reverse logistics providers in the existence of dual-role factors. Expert Systems with Applications, 38(10), 12231-12236. 
Bottani, E., \& Rizzi, A. (2006). A fuzzy TOPSIS methodology to support outsourcing of logistics services. Supply Chain Management: An International Journal, 11(4), 294-308.

Büyüközkan, G., Feyzioğlu, O., \& Nebol, E. (2008). Selection of the strategic alliance partner in logistics value chain. International Journal of Production Economics, 113(1), 148-158.

Cao, J., Cao, G., \& Wang, W. W. (2007, November). A hybrid MCMD integrated borda function and gray rational analysis for 3PLs selection. InGrey Systems and Intelligent Services, 2007. GSIS 2007. IEEE International Conference on (pp. 215-220). IEEE.

Cao, J., Wang, W. W., \& Cao, G. (2007, August). Integration of the social welfare function and TOPSIS algorithm for 3PL selection. In Fuzzy Systems and Knowledge Discovery, 2007. FSKD 2007. Fourth International Conference on (Vol. 3, pp. 596-600). IEEE.

Chen, F. Y., Hum, S. H., \& Sun, J. (2001). Analysis of third-party warehousing contracts with commitments. European Journal of Operational Research, 131(3), 603-610.

ÇAKIR, E., TOZAN, H., \& VAYVAY, Ö. (2009). A method for selecting third party logistic service provider using fuzzy AHP. Deniz Bilimleri ve Mühendisliği Dergisi, 5(3), 38-54

Doyle, J., \& Green, R. (1993). Data envelopment analysis and multiple criteria decision making. Omega, 21(6), 713-715.

Efendigil, T., Önüt, S., \& Kongar, E. (2008). A holistic approach for selecting a third-party reverse logistics provider in the presence of vagueness.Computers \& Industrial Engineering, 54(2), 269287.

Fontela, E., \& Gabus, A. (1976). The DEMATEL observer. DEMATEL' 1976 Report. Battelle Geneva Research Centre, Geneva, Switzerland

Fu, K., Xu, J., Zhang, Q., \& Miao, Z. (2010). An AHP-based decision support model for 3PL evaluation. 7th International Conference on Service Systems and Service Management (ICSSSM), 28-30 June, Tokyo, 1-6

Gabus, A., \& Fontela, E. (1972). World problems, an invitation to further thought within the framework of DEMATEL. Battelle Geneva Research Centre, Geneva, Switzerland

Gabus, A., \& Fontela, E. (1973). Perceptions of the world problematique: communication procedure, communicating with those bearing collective responsibility. Battelle Geneva Research Centre, Geneva, Switzerland

Govindan, K., Grigore, M.C., \& Kannan, D. (2010). Ranking of third party logistics provider using fuzzy ELECTRE II. 40th International Conference on Computers and Industrial Engineering (CIE), 25-28 July, 1-5

Göl, H., \& Çatay, B. (2007). Third-party logistics provider selection: insights from a Turkish automotive company. Supply Chain Management: An International Journal, 12(6), 379-384.

Guoyi, X., \& Xiaohua, C. (2011). Research on the third party logistics supplier selection evaluation based on AHP and entropy. International Conference on Mechatronic Science, Electric Engineering and Computer, August 19-22, Jilin, China, 788-792

Gupta, R., Sachdeva, A., \& Bhardwaj, A. (2010). Selection of 3pl service provider using integrated fuzzy delphi and fuzzy TOPSIS. Proceedings of the World Congress on Engineering and Computer Science 2, 20-22

Hamdan, A., \& Rogers, K.J. (2008). Evaluating the efficiency of 3PL logistics operations. International Journal of Production Economics, 113(1), 235-244.

Hertz, S., \& Alfredsson, M. (2003). Strategic development of third party logistics providers. Industrial Marketing Management, 32(2), 139-149.

Işıklar, G., Alptekin, E., \& Büyüközkan, G. (2007). Application of a hybrid intelligent decision support model in logistics outsourcing. Computers \& Operations Research, 34(12), 3701-3714.

Jayant, A., Gupta, P., Garg, S. K., \& Khan, M. (2014). TOPSIS-AHP based approach for selection of reverse logistics service provider: a case study of mobile phone industry. Procedia Engineering, 97, 2147-2156.

Jharkharia, S., \& Shankar, R. (2007). Selection of logistics service provider: An analytic network process (ANP) approach. Omega, 35(3), 274-289. 
Kannan, G., Pokharel, S., \& Kumar, P. S. (2009). A hybrid approach using ISM and fuzzy TOPSIS for the selection of reverse logistics provider.Resources, Conservation and Recycling, 54(1), 28-36.

Karagul, H., \& Albayrakoglu, M. (2007). Selecting a third-party logistics provider for an automotive company: an analytic hieararchy process model. ISAHP 2007, August 3-6, Viña Del Mar, Chile.

Kumar, M., Vrat, P., \& Shankar, R. (2006) A multiobjective 3PL allocation problem for fish distribution. International Journal of Physical Distribution \& Logistics Management, 36(9), 702715

Lehmusvaara, A., Tuominen, M., \& Korpela, J. (1999). An integrated approach fort truck carrier selection. International Journal of Logistics: Research and Applications 2(1), 5-20.

Lei, F., \& Long, Y. (2011). Research on selection of third-party logistics enterprise based on the extenics. Communication Software and Networks (ICCSN), 2011 IEEE 3rd International Conference, 27-29 May, 242-246.

Li, C., Sun, Y., \& Du, Y. (2008, July). Selection of 3PL service suppliers using a fuzzy analytic network process. In Control and Decision Conference, 2008. CCDC 2008. Chinese (pp. 2174-2179). IEEE.

Li, F., Li, L., Jin, C., Wang, R., Wang, H., \& Yang, L. (2012) A 3PL supplier selection model based on fuzzy sets. Computers \& Operations Research, 39, 1879-1884.

Liou, J.J.H., \& Chuang, Y.T. (2010). Developing a hybrid multi-criteria model for selection of outsourcing providers. Expert Systems with Applications 37(5), 3755-3761.

Liu, H. T., \& Wang, W. K. (2009). An integrated fuzzy approach for provider evaluation and selection in third-party logistics. Expert Systems with Applications, 36(3), 4387-4398.

Meade, L., \& Sarkis, J. (2002). A conceptual model for selecting and evaluating third-party reverse logistics providers. Supply Chain Management: An International Journal, 7(5), 283-295.

Min, H., \& Park, B. I. (2008). A hybrid Data Envelopment Analysis and simulation methodology for measuring capacity utilisation and throughput efficiency of container terminals. International Journal of Logistics Systems and Management, 4(6), 650-672.

Qureshi, M.N., Kumar, D., \& Kumar, P. (2007). Selection of potencial 3PL service providers using TOPSIS with interval data. In: Annals ofthe 2007 IEEE International Conference on Industrial Engineering and Engineering Management, 30 May - 02 June, Singapore, 1512-1516

Saaty, T.L. (1990). How to mark a decision: The analytic hierarchy process. European Journal of Operational Research 48, 9-26

Saaty, T.L. (1996). Decision making with dependence and feedback: The analytic network process. Pittsburgh, PA: RWS Publications

Saen, R. F. (2010). A new model for selecting third-party reverse logistics providers in the presence of multiple dual-role factors. The International Journal of Advanced Manufacturing Technology, 46(14), 405-410.

Sarkis, J. (2000). A comparative analysis of DEA as a discrete alternative multiple criteria decision tool. European Journal of Operational Research,123(3), 543-557.

Sarkis, J., \& Talluri, S. (2002). A synergistic framework for evaluating business process improvements. International Journal of Flexible Manufacturing Systems, 14(1), 53-71.

Soh, S. (2010). A decision model for evaluating third-party logistics providers using fuzzy analytic hierarchy process. African Journal of Business Management, 4(3), 339-349.

Thakkar, J., Deshmukh, S.G., Gupta, A.D., \& Shankar, R. (2005). Selection of third-party logistics (3PL): A hybrid approach using interpretive structural modelling (ISM) and analytic network process (ANP). Supply Chain Forum: An international Journal 6(1), 32-46.

Tohumcu, Z., \& Karasakal, E. (2010). R\&D project performance evaluation with multiple and interdependent criteria. IEEE Transacitons on Engineering Management, 57(4), 620-633.

Tsai, W.H., \& Hsu, W. (2010). A novel hybrid model based on DEMATEL and ANP for selecting cost of quality model development. Total Quality Management \& Business Excellence 21(4), 439-456.

Tseng, M.L. (2010). Implementation and performance evaluation using the fuzzy network balanced scorecard. Computers and Education 55(1), 188-201. 
Tseng, M. L. (2009). Application of ANP and DEMATEL to evaluate the decision-making of municipal solid waste management in Metro Manila.Environmental Monitoring and Assessment, 156(1-4), 181-197.

$\mathrm{Wu}, \mathrm{W} . \mathrm{W} .$, \& Lee, Y. T. (2007). Developing global managers' competencies using the fuzzy DEMATEL method. Expert Systems with Applications, 32(2), 499-507.

Zhang, H., Li, X., \& Liu, W. (2005). An AHP/DEA methodology for 3PL vendor selection in 4PL. In Computer Supported Cooperative Work in Design II (pp. 646-655). Springer Berlin Heidelberg.

Zhou, G., Min, H., Xu, C., \& Cao, Z. (2008). Evaluating the comparative efficiency of Chinese thirdparty logistics providers using data envelopment analysis. International Journal of Physical Distribution \& Logistics Management, 38(4), 262-279.

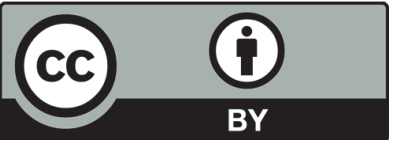

(C) 2016 by the authors; licensee Growing Science, Canada. This is an open access article distributed under the terms and conditions of the Creative Commons Attribution (CC-BY) license (http://creativecommons.org/licenses/by/4.0/). 